Pacific Journal of Mathematics

ON THE DEGREE OF THE MINIMAL POLYNOMIAL OF A 


\title{
ON THE DEGREE OF THE MINIMAL POLYNOMIAL OF A COMMUTATOR OPERATOR
}

\author{
M. Shafqat Ali and Marvin Marcus
}

Let $A$ be an $n$-square matrix over a field $F$ of characteristic 0 . The additive commutator operator defined by $A$, $T_{A} X=A X-X A$, can be regarded as a linear transformation on the space of all $n$-square matrices $X$ over $F$. Following earlier papers by 0 . Taussky and $H$. Wielandt and one of the present authors, we show that the degree of the minimal polynomial of $T_{A}$ is always odd and at least

$$
2[m+E+(k-2) e-k]+1
$$

where $m$ is the degree of the minimal polynomial of $A, k$ is the number of distinct eigenvalues of $A$, and $E(e)$ is the largest (least) integer among the degrees of the distinct highest degree elementary divisors of the characteristic matrix of $A$.

The purpose of this paper is two-fold: first we obtain a count of the number of distinct differences of the form $z_{i}-z_{j}, i \neq j$, where $z_{1}, \cdots, z_{n}$ are distinct elements of a field $F$ of characteristic 0 ; second we apply this to prove a result on the parity and magnitude of the degree of the minimal polynomial of a matrix commutator. Annihilating polynomials for commutators were originally considered by Taussky and Wielandt in a paper in 1962 [5] and then again by one of the present authors in 1964 [2] (see also [1] and [6]).

To be precise let $A$ be an $n$-square matrix over $F$ and consider the linear transformation $T_{A}$ defined on the space $M_{n}(F)$ of $n$-square matrices over $F$ :

$$
T_{A} X=A X-X A, \quad X \in M_{n}(F) .
$$

Then $T_{A}$ is called the commutator operator defined by $A$. The transformation $T_{A}$ has a matrix representation $A \otimes I_{n}-I_{n} \otimes A$ where $\otimes$ indicates Kronecker product [3, p. 8]. The minimal polynomial of $T_{A}$ is called the minimal polynomial of the commutator operator (1).

In an appropriate algebraic extension field $K$ of $F$ the elementary divisors of the characteristic matrix of $A$ are powers of binomials. Let $\gamma_{1}, \cdots, \gamma_{k}$ be the distinct eigenvalues of $A$, let $e_{i}$ be the degree of the highest degree elementary divisor of the characteristic matrix of $A$ involving $\gamma_{i}, i=1, \cdots, k$, let $E=\max _{i} e_{i}, e=\min _{i} e_{i}$, and let $m$ be the degree of the minimal polynomial of $A$.

THEOREM 1. If $F$ is a field of characteristic zero then the degree 
of the minimal polynomial of the commutator operator $T_{A}$ is always odd and at least

$$
2[m+E+(k-2) e-k]+1 .
$$

In order to prove Theorem 1 we shall find it necessary to consider the following problem: given $n$ distinct numbers $z_{1}, \cdots, z_{n}$ in $F$ how many distinct differences are there of the form $z_{i}-z_{j}, i \neq j, i, j=$ $1, \cdots, n$ ? Of course, the number can be as small as $2 n-2$ by simply taking $z_{i}=i, i=1, \cdots, n$. As an application of the Perron-Frobenius theorem on nonnegative matrices the following result, used to prove Theorem 1, may be of some independent interest.

THEOREM 2. Let $z_{1}, \cdots, z_{n}$ be $n$ distinct element in a field $F$ of characteristic 0 . Then there are always at least $2 n-2$ distinct nonzero differences of the form $z_{i}-z_{j}, i \neq j, i, j=1, \cdots, n$.

II. Proofs. We begin with the proof of Theorem 2. We shall show in fact that there exists a permutation $\phi \in S_{n}$ (the symmetric group of degree $n$ ) for which the $2 n-2$ elements

$$
\pm\left(z_{\varphi(1)}-z_{\varphi(2)}\right), \cdots, \pm\left(z_{\varphi(1)}-z_{\varphi(n)}\right)
$$

are distinct. If this is not the case then for every $\varphi \in S_{n}$ there must exist integers $p$ and $q, p \neq q$, such that

$$
z_{\varphi(1)}-z_{\varphi(p)}=z_{\varphi(q)}-z_{\varphi(1)} .
$$

For, obviously the two sets of numbers (2) obtained by choosing first the + signs and then the - signs each consist of $n-1$ distinct differences. Thus if there is to be an overlap, (3) must hold and we have $z_{\varphi(1)}=\frac{1}{2} z_{\varphi(p)}+\frac{1}{2} z_{\varphi(q)}$. Since $\varphi$ is arbitrary we can write $z_{i}=$ $\sum_{j=1}^{n} a_{i j} z_{j}, i=1, \cdots, n$, where for each $i$, there are precisely two values of $j$ for which $a_{i j}=\frac{1}{2}$, and otherwise $a_{i j}=0$. Let $A=\left(a_{i j}\right)$, $z=\left(z_{1}, \cdots, z_{n}\right)$ so that

$$
A z=z \text {. }
$$

The matrix $A$ may or may not be reducible but in any event there exists an $n$-square permutation matrix $P$ such that

$$
P^{T} A P=\left[\begin{array}{cccccc}
A_{1} & 0 & \cdot & \cdot & \cdot & 0 \\
* & A_{2} & & & \vdots \\
\vdots & & \cdot & \cdot & & 0 \\
* & . & \cdot & \cdot & * & A_{m}
\end{array}\right]
$$

and moreover each of the square matrices appearing along the main 
diagonal in (5) is irreducible or 1-square. Now suppose $A_{1}$ is $k$-square. Since each row of $A$ (and hence of $P^{T} A P$ ) has precisely two nonzero entries in it, it follows that $k \geqq 2$. From (4) we have

$$
P^{T} A P x=x
$$

where $x=P^{T} z$. Let $y=\left(x_{1}, \cdots, x_{k}\right)$ and we see that (5) and (6) imply that

$$
\left(A_{1}-I_{k}\right) y=0 \text {. }
$$

Since $F$ has characteristic 0 it contains the rationals and $A_{1}$ can be regarded as a nonnegative, irreducible, row-stochastic matrix. By the Perron-Frobenius theorem [3, p. 124] we can immediately conclude that 1 is a simple eigenvalue of $A_{1}$ and hence the nullity of $A_{1}-I_{k}$ over the rationals is $k-1$. But the nullity is unchanged by regarding $A_{1}-I_{k}$ as a matrix over any extension field of $F$. Now $e=(1, \cdots, 1)$ is in the null space of $A_{1}-I_{k}$ and hence any vector $y$ satisfying (7) must be a multiple of $e$. Since $k \geqq 2$ we conclude that at least two of the $y_{i}$ are the same and hence that at least two of the $z_{i}$ are the same. This contradiction completes the proof.

The preceding result has an immediate corollary. We let $\nu(\mathfrak{U})$ denote the cardinality of a set $\mathfrak{U}$.

Corollary. Let $\mathfrak{U}$ be the set of all distinct non-zero differences of the form $z_{i}-z_{j}, i \neq j$. Then $\nu(\mathfrak{H})$ is even and at least $2 n-2$.

Proof. According to the preceding argument there exists a permutation $\varphi \in S_{n}$ such that the $2 n-2$ differences $\pm\left(z_{\varphi(1)}-z_{\varphi(i)}\right), i=$ $2, \cdots, n$, are distinct. We can assume without loss of generality that $\varphi$ is the identity. Let

$$
\begin{aligned}
\alpha & =\left\{z_{1}-z_{i}, i=2, \cdots, n\right\}, \\
\beta & =\left\{z_{i}-z_{1}, i=2, \cdots, n\right\},
\end{aligned}
$$

$\nu(\alpha)=\nu(\beta)=n-1$. If $\mathfrak{I}=\alpha \cup \beta$ then we are finished. So assume that there exist integers $i_{1}, j_{1}, 1<i_{1} \leqq n, 1<j_{1} \leqq n, i_{1} \neq j_{1}$ such that $z_{i_{1}}-z_{j_{\imath}} \notin \alpha \cup \beta$. But then clearly $z_{j_{1}}-z_{i_{1}} \in \alpha \cup \beta$. For if $z_{j_{1}}-z_{i_{1}} \in \alpha$, say, then $z_{j_{1}}-z_{\imath_{1}}=z_{1}-z_{t}$ and hence $z_{i_{1}}-z_{j_{1}}=z_{t}-z_{1}$ in contradiction to the assumption that $z_{i_{1}}-z_{j_{i}} \in \alpha \cup \beta$. Now set

$$
\alpha_{1}=\alpha \cup\left\{z_{i_{1}}-z_{j_{1}}\right\}, \quad \beta_{1}=\beta \cup\left\{z_{j_{1}}-z_{i_{1}}\right\} .
$$

Clearly $\nu\left(\alpha_{1} \cup \beta_{1}\right)=\nu(\alpha \cup \beta)+2$ and if $\alpha_{1} \cup \beta_{1} \neq \mathfrak{U}$ we can repeat the preceding argument with $\alpha_{1}$ and $\beta_{1}$ replacing $\alpha$ and $\beta$ to obtain $\alpha_{2}$ and $\beta_{2}$ such that $\nu\left(\alpha_{2} \cup \beta_{2}\right)=\nu\left(\alpha_{1} \cup \beta_{1}\right)+2=\nu(\alpha \cup \beta)+4=(2 n-2)+4$. This procedure can obviously be continued until $\mathfrak{A}$ is exhausted. 
To prove Theorem 1 we use a well known theorem of Roth [4]: if $\left(\lambda-\gamma_{i}\right)^{p}$ and $\left(\lambda-\gamma_{j}\right)^{q}$ are a pair of elementary divisors of the characteristic matrix of $A$ then corresponding to these is a list of elementary divisors of the characteristic matrix of $A \otimes I_{n}-I_{n} \otimes A$ :

$$
\left(\lambda-\left(\gamma_{i}-\gamma_{j}\right)\right)^{t},
$$

where $t \leqq p+q-1$. According to Theorem 2 there are at least $(2 k-2)$ distinct nonzero differences of the form $\pm\left(\gamma_{\varphi(1)}-\gamma_{\varphi(j)}\right), j=$ $2, \cdots, k$, and it is simply a matter of notational convenience to assume that these $2 k-2$ differences are $\pm\left(\gamma_{1}-\gamma_{i}\right), i=2, \cdots k$. The highest degree elementary divisor involving the zero eigenvalue of the characteristic matrix of $A \otimes I_{n}-I_{n} \otimes A$ is

$$
\lambda^{2 E-1}
$$

By the corollary, the set $\mathfrak{A}$ of all nonzero distinct eigenvalues of $T_{A}$ is of the form

$$
\begin{aligned}
\mathfrak{A} & =\left\{ \pm\left(\gamma_{1}-\gamma_{i}\right), i=2, \cdots, k\right\} \\
& \cup\left\{ \pm\left(\gamma_{i_{t}}-\gamma_{j_{t}}\right), t=1, \cdots, p\right\} .
\end{aligned}
$$

Now suppose the highest degree elementary divisors of the characteristic matrix of $A \otimes I_{n}-I_{n} \otimes A$ involving the nonzero distinct. eigenvalues of $T_{A}$ are:

$$
\begin{aligned}
& \left(\lambda-\left(\gamma_{1}-\gamma_{i}\right)\right)^{e r_{i}{ }^{e} e_{s_{i}}-1},\left(\lambda-\left(\gamma_{i}-\gamma_{1}\right)\right)^{e^{e} r_{i}{ }^{+e} s_{i}-1}, i=2, \cdots, k, \\
& \left(\lambda-\left(\gamma_{i_{t}}-\gamma_{j_{t}}\right)\right)^{e_{m_{t}}+e_{q_{t}}-1},\left(\lambda-\left(\gamma_{j_{t}}-\gamma_{i_{t}}\right)\right)^{e_{m_{t}}+e_{q_{t}}-1}, t=1, \cdots, p \text {. }
\end{aligned}
$$

Thus the degree of the minimal polynomial of $T_{A}$ is

$$
d=2 E-1+2 \sum_{i=2}^{k}\left(e_{r_{i}}+e_{s_{i}}-1\right)+2 \sum_{t=1}^{p}\left(e_{m_{t}}+e_{q_{t}}-1\right),
$$

an odd integer. Observe that

$$
d \geqq(2 E-1)+2 \sum_{i=2}^{k}\left(e_{1}+e_{i}-1\right)+2 \sum_{t=1}^{p}\left(e_{i_{t}}+e_{j_{t}}-1\right),
$$

and hence

$$
\begin{aligned}
d & \geqq(2 E-1)+2 \sum_{i=2}^{k} e_{i}+2(k-1)\left(e_{1}-1\right) \\
& =2 E-1+2\left(m-e_{1}\right)+2(k-1)\left(e_{1}-1\right) \\
& \geqq 2[m+E+(k-2) e-k]+1 .
\end{aligned}
$$

This completes the proof of Theorem 1 . 


\section{REFERENCES}

1. Fergus Gaines, Kato-Taussky-Wielandt commutator relations, Linear Algebra and Its Applications, 1 (1968), 127-138.

2. Marvin Marcus, The minimal polynomial of a commutator, Portugaliae Math., 25, (1964), 73-76.

3. Marvin Marcus and Henryk Minc, $A$ Survey of Matrix Theory and Matrix Inequalities, Prindle, Weber and Schmidt, Boston, 1969.

4. W. E. Roth, On direct product matrices, Bull. Amer. Math. Soc., 40 (1934), 461468.

5. O. Taussky and $\mathrm{H}$. Wielandt, Linear relations between higher additive commutators, Proc. Amer. Math. Soc., 13 (1962), 732-735.

6. O. Taussky, A generalization of matrix commutativity, Linear Algebra and Its Applications, 2 (1969), 349-353.

Received June 4, 1970. The research of both authors was supported in part by the U.S. Air Force Office of Scientific Research under grant AFOSR 698-67.

University of Islamabad, Islamabad, Pakistan and

California State College, Long Beach, California

University of California, Santa Barbara 



\title{
PACIFIC JOURNAL OF MATHEMATICS
}

\author{
EDITORS
}

\author{
H. SAMelson \\ Stanford University \\ Stanford, California 94305 \\ C. R. HoBBy \\ University of Washington \\ Seattle, Washington 98105
}

J. DugunduI

Department of Mathematics

University of Southern California

Los Angeles, California 90007

RICHARD ARENS

University of California

Los Angeles, California 90024

\section{ASSOCIATE EDITORS}

\author{
E. F. BeCKENBACH
}

B. H. NEUMANN

F. WoLF

K. YOSHIDA

\section{SUPPORTING INSTITUTIONS}

\author{
UNIVERSITY OF BRITISH COLUMBIA \\ CALIFORNIA INSTITUTE OF TECHNOLOGY \\ UNIVERSITY OF CALIFORNIA \\ MONTANA STATE UNIVERSITY \\ UNIVERSITY OF NEVADA \\ NEW MEXICO STATE UNIVERSITY \\ OREGON STATE UNIVERSITY \\ UNIVERSITY OF OREGON \\ OSAKA UNIVERSITY \\ UNIVERSITY OF SOUTHERN CALIFORNIA
}

\author{
STANFORD UNIVERSITY \\ UNIVERSITY OF TOKYO \\ UNIVERSITY OF UTAH \\ WASHINGTON STATE UNIVERSITY \\ UNIVERSITY OF WASHINGTON \\ AMERICAN MATHEMATICAL SOCIETY \\ CHEVRON RESEARCH CORPORATION \\ NAVAL WEAPONS CENTER
}

The Supporting Institutions listed above contribute to the cost of publication of this Journal, but they are not owners or publishers and have no responsibility for its content or policies.

Mathematical papers intended for publication in the Pacific Journal of Mathematics should be in typed form or offset-reproduced, (not dittoed), double spaced with large margins. Underline Greek letters in red, German in green, and script in blue. The first paragraph or two must be capable of being used separately as a synopsis of the entire paper. The editorial "we" must not be used in the synopsis, and items of the bibliography should not be cited there unless absolutely necessary, in which case they must be identified by author and Journal, rather than by item number. Manuscripts, in duplicate if possible, may be sent to any one of the four editors. Please classify according to the scheme of Math. Rev. Index to Vol. 39. All other communications to the editors should be addressed to the managing editor, Richard Arens, University of California, Los Angeles, California, 90024.

50 reprints are provided free for each article; additional copies may be obtained at cost in multiples of 50 .

The Pacific Journal of Mathematics is published monthly. Effective with Volume 16 the price per volume (3 numbers) is $\$ 8.00$; single issues, $\$ 3.00$. Special price for current issues to individual faculty members of supporting institutions and to individual members of the American Mathematical Society: $\$ 4.00$ per volume; single issues $\$ 1.50$. Back numbers are available.

Subscriptions, orders for back numbers, and changes of address should be sent to Pacific Journal of Mathematics, 103 Highland Boulevard, Berkeley, California, 94708.

PUBLISHED BY PACIFIC JOURNAL OF MATHEMATICS, A NON-PROFIT CORPORATION

Printed at Kokusai Bunken Insatsusha (International Academic Printing Co., Ltd.), 7-17, Fujimi 2-chome, Chiyoda-ku, Tokyo, Japan. 


\section{Pacific Journal of Mathematics}

\section{Vol. 37, No. $3 \quad$ March, 1971}

Mohammad Shafqat Ali and Marvin David Marcus, On the degree of the

minimal polynomial of a commutator operator ................ 561

Howard Anton and William J. Pervin, Integration on topological

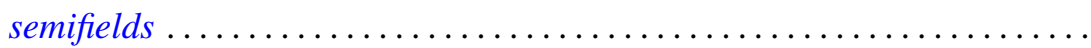

Martin Bartelt, Multipliers and operator algebras on bounded analytic

functions .................................... 575

Donald Earl Bennett, Aposyndetic properties of unicoherent continua ...... 585

James W. Bond, Lie algebras of genus one and genus two ............. 591

Mario Borelli, The cohomology of divisorial varieties ............... 617

Carlos R. Borges, How to recognize homeomorphisms and isometries ....... 625

J. C. Breckenridge, Burkill-Cesari integrals of quasi additive interval

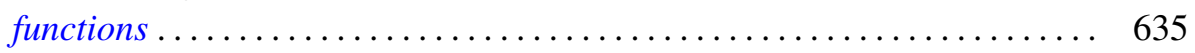

J. Csima, A class of counterexamples on permanents ................ 655

Carl Hanson Fitzgerald, Conformal mappings onto $\omega$-swirly domains . . . . . . 657

Newcomb Greenleaf, Analytic sheaves on Klein surfaces .............. 671

G. Goss and Giovanni Viglino, C-compact and functionally compact

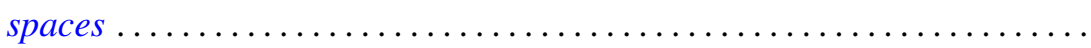

Charles Lemuel Hagopian, Arcwise connectivity of semi-aposyndetic plane

continua ..................................... 683

John Harris and Olga Higgins, Prime generators with parabolic limits ...

David Michael Henry, Stratifiable spaces, semi-stratifiable spaces, and their

relation through mappings .......................

Raymond D. Holmes, On contractive semigroups of mappings ........... 701

Joseph Edmund Kist and P. H. Maserick, BV-functions on semilattices ....... 711

Shûichirô Maeda, On point-free parallelism and Wilcox lattices ........... 725

Gary L. Musser, Linear semiprime $(p ; q)$ radicals ................. 749

William Charles Nemitz and Thomas Paul Whaley, Varieties of implicative

semilattices..................................... 759

Jaroslav Nešetřil, A congruence theorem for asymmetric trees ............ 771

Robert Anthony Nowlan, A study of $H$-spaces via left translations .......... 779

Gert Kjærgaard Pedersen, Atomic and diffuse functionals on a $C^{*}$-algebra ... 795

Tilak Raj Prabhakar, On the other set of the biorthogonal polynomials

suggested by the Laguerre polynomials...

801

Leland Edward Rogers, Mutually aposyndetic products of chainable

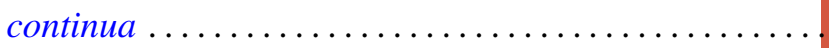

Frederick Stern, An estimate for Wiener integrals connected with squared

error in a Fourier series approximation.

Leonard Paul Sternbach, On k-shrinking and k-boundedly complete basic

sequences and quasi-reflexive spaces .................... 817

Pak-Ken Wong, Modular annihilator $A^{*}$-algebras ........ 